\title{
CONDIÇÕES PARA A DEMOCRACIA OU DEMOCRACIAS SEM CONDIÇÕES: DILEMAS DE UM PENSAMENTO POLITIICO CONTEMPORÂNEO ${ }^{1}$
}

\author{
CONDITIONS FOR DEMOCRACY OR DEMOCRACY WITHOUT \\ CONDITIONS: DILEMMAS OF A CONTEMPORARY \\ POLITICAL THOUGHT
}

\author{
Gustavo Müller²
}

\section{RESUMO}

O objetivo deste artigo é contribuir para o debate teórico acerca dos dilemas enfrentados pelo pensamento democrático neste início de século XXI. O artigo segue a metodologia comparativa, usando como material empírico os dados relacionados à avaliação do grau de desenvolvimento democrático dos novos membros da União Europeia, Bálcãs e ex-Repúblicas Soviéticas, disponíveis no site da Freedom House. A hipótese deste trabalho é a de que a busca por um conceito operacional de democracia, associado à hegemonia da corrente neoinstitucionalista, limitou o alcance explicativo das ciências sociais, e a conclusão do artigo é a de que um conjunto amplo de variáveis precisa ser levado em consideração para que se compreenda o desenvolvimento da democracia nos mais diversos contextos.

Palavras-chave: Democracia. Sociedade Civil. Governabilidade. Corrupção.

\footnotetext{
${ }^{1}$ Versão adaptada do paper apresentado no Grupo de Trabalho de Política Internacional no I Seminário Nacional de Ciência Política: Democracia em Debate, promovido pelo Programa de Pós-Graduação em Ciência Política da UFRGS, de 03 a 05 de setembro de 2008. O autor dedica este trabalho ao pai.

2 Professor Adjunto de Ciência Política da Universidade Federal de Santa Maria
} 


\section{ABSTRACT}

The objective of this article is to contribute for the theoretical debate concerning the dilemmas faced by the democratic thought in that century beginning XXI. The article follows the comparative methodology using as empiric material the data related to the evaluation of the degree of democratic development of the new members of the European Union, Balkans and ex-Soviet Republics, available in Freedom House site. The hypothesis of this work is the that the search for an operational concept of democracy, associate to the hegemony of the newinstitutionalism school, limited the explanatory reach of the social sciences, and the conclusion of the article is the that a wide group of variables needs to be taken into account for the development of the democracy to be understood in the most several contexts.

Keywords: Democracy. Civil Society. Accountability. Corruption.

\section{INTRODUÇÃO}

No pensamento político atual, o debate em torno da democracia ocupa, sem sombra de dúvidas, o centro das atenções, não somente dos cientistas sociais, mas de todos os atores que, de uma forma ou de outra, estão inseridos no debate público. O que este artigo se propõe é fazer um breve levantamento dos temas mais frequentes da ciência política acerca da democracia, e dos desafios da consolidação das democracias de terceira onda, sobretudo no Leste Europeu.

Para cumprir tal tarefa, este artigo foi dividido em quatro partes (contando com esta introdução); na segunda parte, foi realizada uma revisão breve da literatura sobre democracia, seus princípios e seus dilemas gerais. Na terceira parte, foram introduzidos dados empíricos disponíveis no site da Freedom House. E, por fim, uma parte conclusiva unindo a análise teórica e análise dos dados.

A hipótese geral que orienta esta reflexão é a de que a busca por um conceito operacional de democracia pelos cientistas sociais e o avanço das teorias neoinstitucionalistas produziram paradoxos teóricos que se afastam da compreensão dos conjuntos de fatores que determinam a existência ou a qualificação de regimes como "democráticos" nos mais diversos contextos históricos e culturais.

Esse paradoxo se manifesta, segundo esta hipótese, em um hiato entre a existência de instituições eleitorais e avanços qualitativos na construção de instrumentos de accountability, tais como, fortalecimento da sociedade civil, melhorias no grau de governabilidade e controle da corrupção.

Cabe, ainda, salientar que, como aponta Munck (2009), a construção de índices que permitam "mensurar" a vitalidade dos regimes democráticos é uma tarefa árdua e que, na maioria das vezes, fica comprimida entre uma visão minimalista e maximalista. Por conta disso, os dados disponíveis no site da Freedom House parecem adequados para um trabalho de caráter exploratório como este e que não pretende estabelecer nenhuma relação rigorosa entre causas e efeitos. Pretende apenas apontar perspectivas teóricas que poderão ser aprimoradas num futuro próximo, com uma maior aproximação entre teoria e empiria.

Por fim, cabe ressaltar que os casos escolhidos se devem a razões geopolíticas e todos eles pertencem ao espectro geográfico e político do continente europeu. 


\section{DEMOCRACIA: DEFINIÇÃO OU CONCEITO}

A busca por uma definição exata de "democracia" é um tema recorrente na filosofia política ocidental, entendendo "definição" como uma categoria de elevado nível de abstração, que visa a revelar uma realidade em si ou uma concepção ideal, com um sentido acabado em torno do que seja a forma mais perfeita de determinado ato.

Já a tentativa de "conceituar" o que seja uma "democracia" é uma tarefa que permite partir de uma realidade empírica, na qual os conceitos são construídos com o objetivo de sintetizar determinados fenômenos. É verdade que, dependendo de como se posiciona o leitor, a própria caracterização do que possa ser entendido como "definição" ou "conceito" pode ser controverso. Todavia, a opção por essa distinção entre as duas categorias busca salientar, precisamente, as imensas possibilidades de variáveis a serem incluídas quando se procura conceituar um regime político como "democrático".

Em um artigo elucidativo e ao mesmo tempo perplexo (no qual o título do presente trabalho foi inspirado), Alain Rouquié (1985) destaca os esforços realizados nos mais diversos contextos sociais, pela maturação de um regime, ou sistema, de representação política, ou seja, uma forma institucionalizada de resolução dos conflitos de interesses gerados no interior das sociedades.

O autor salienta que, em determinados países, como no Líbano, grupos rivais podem chegar a um consenso mínimo a respeito das regras do jogo ou, em suas palavras, "democracias concordatárias". (ROUQUIÉ, 1985, p. 39). Tais regimes encarnariam o que, ad hoc, poderiam ser classificadas como "democracias sem condições", uma vez que a durabilidade da adesão dos diversos segmentos sociais, culturais, étnicos ou religiosos a canais considerados legítimos é duvidosa, tornando, assim, os regimes democráticos instáveis.

Mas quais seriam as condições para que se possa conceituar um regime político como democrático? Existem de fato environments nos quais a democracia, tal qual uma planta, germina, cresce e dá frutos?

É quase impossível deixar de fazer referência ao papel da esfera societal, tão ressaltado por Tocqueville (1998), para explicar o funcionamento da democracia nos Estados Unidos ou, ainda, a influência do fator associativo, ou mais especificamente, "capital social", no desempenho das instituições governamentais na Itália da década de 1970. (PUTNAM, 1996).

Todavia, Tocqueville e Putnam remetem-nos ao antigo debate sobre os pré-requisitos sociais para a democracia, isto é, se há, de fato, condicionamentos socioeconômicos ou culturais que propiciem a construção de democracias sólidas. No final dos anos 1950, tais pré-requisitos foram entendidos basicamente como desenvolvimento econômico (LIPSET, 1967). Embora seja tentadora a ideia de que possa haver, de fato, uma forte correlação entre democracia e desenvolvimento, os casos de regimes representativos ou "democracias sem condições" em contextos de fortes desigualdades sociais, como a Índia, continuam a representar um desafio teórico e empírico para os adeptos dos pré-requisitos. (ROUQUIÉ, 1985, p 42).

Além do mais, para muitos analistas dos autoritarismos latino-americanos do final da década de 1960 e início dos anos 1970, os surtos de crescimento econômico, anteriores ao amadurecimento de uma ordem política institucionalizada, geraram uma sobrecarga de demandas sociais aos sistemas políticos (HUNTINGTON, 1968), desaguando-se, assim, nos Estados Burocráticos-Autoritários. (O'DONNELL, 1990).

Para esses autores, genericamente designados como adeptos da "teoria da modernização", os países de Terceiro Mundo não completaram a plena expansão da cidadania nas esferas 
política, econômica e social, conforme a interpretação sociológica do desenvolvimento europeu, proposta por Marshall (1992 [1950]).

\subsection{DEMOCRACIA DE PROCEDIMENTO OU POLIARQUIAS}

Ainda em referência aos textos canônicos da teoria democrática, cabe citar os esforços realizados por Schumpeter e Dahl, para a operacionalização de um conceito de democracia, esforço no qual, aliás, Kelsen (2000 [1955]) poderia ser incluído, devido à estreita relação que este faz entre democracia e regras formais, cristalizadas na norma jurídica oriunda do poder emanado do Estado.

Essa visão da democracia como um conjunto de regras formais, ou regras mínimas, foi sintetizada por Schumpeter (1968, p. 328) no conceito de "democracia de procedimentos", segundo o qual, "O método democrático é um sistema institucional para a tomada de decisões políticas, no qual o individuo adquire o poder de decidir mediante uma luta competitiva pelo voto do eleitor".

Schumpeter chega a esse conceito depois de expor a razão pela qual considera inviável a execução da democracia segundo sua essência mais pura. De acordo com a visão schumpeteriana, a encarnação da "vontade geral" é irrealizável num sistema de representação política, uma vez que não seria possível a soma das vontades individuais sem que se gerassem contradições.

Nessa mesma linha, por considerar as democracias vigentes como uma mera aproximação do que seria o ideal democrático, Dahl (1997) sugere a utilização do conceito de "poliarquia" para designar os regimes políticos nos quais as ações dos governantes possuem, ainda que de forma um tanto que distante, o consentimento dos cidadãos..

Todavia, Dahl (1997, p. 26-27) estabelece algumas condições básicas para que os regimes possam, de fato, serem considerados "poliarquias". Tais condições podem ser divididas em três grupos: liberdade de formular preferências, liberdade de expressar preferências e ter suas preferências (dos cidadãos) consideradas pelos governos. A partir de tais pré-condições, Dahl fornece instrumentos operacionais para que se possa mensurar o grau de sedimentação dos procedimentos democráticos, como sugeriu Schumpeter, ou das "poliarquias", nas palavras de Dahl. Contudo, o principal instrumento sugerido pelo autor para que se investigue acerca da efetividade das "poliarquias" é o grau de liberdade conferido às oposições.

Para Dahl (1997, p. 47):

Quanto menores os obstáculos à contestação pública e maior a população incluída no sistema político, mais dificuldade terá o governo de um país em adotar e aplicar políticas que exijam o exercício de sanções extremas contra uma porção maior do que uma pequena porcentagem da população.

\subsection{DEMOCRACIAS E INSTITUCIONALISMOS}

Sendo as democracias, ou "poliarquias", mensuráveis em última instância, pela frequência e intensidade das disputas eleitorais, conforme sugeriram Schumpeter e Dahl, o debate teórico foi, de certo modo, reorientado. A busca por condicionamentos históricos e estruturais ficou ofuscada pela procura de requisitos ou formatos institucionais que permitissem qualificar um determinado regime como "democrático" ou "não-democrático", o que coincidiu com o avanço da perspectiva teórica neoinstitucionalista sob a agenda da ciência política neste final de século. (PETERS, 1996, p. 208). 
Em outras palavras, o debate sobre a democracia se afastou da perspectiva sociológica, para passar a girar em torno das características institucionais que favoreceriam ou não o funcionamento dos regimes democráticos, sem maiores considerações sobre demais elementos que poderiam interagir como variáveis intervenientes.

Dentre os traços institucionais envolvidos no debate sobre o funcionamento do regime democrático, pode-se destacar a forma de governo, parlamentarismo ou presidencialismo (LINZ; VALENZUELA, 1994), sistemas eleitorais que agrupariam as fórmulas majoritárias no conceito de "democracias majoritárias", e fórmulas eleitorais proporcionais no grupo das "democracias consorciativas" (LIJPHRAR, 1994).

Não obstante, em abordagens mais amplas sobre o papel das instituições, como variáveis que favoreçam ou não a existência de regimes democráticos, é possível perceber um "reencontro" com a perspectiva histórico-sociológica. Esse reencontro é perceptível, tanto nos conceitos de aggregative ou integrative political processes (MARCH; OLSEN, 1989, p. 118), como no conceito de path dependence. (PIERSON, 2004).

No primeiro caso, os dois conceitos envolvem um comportamento diferenciado que se reflete no papel desempenhado pelas instituições, não somente nas funções governativas, mas também na relação entre instituições e sociedade. 0 conceito de aggregative political processes presume a existência de coalizões de interesses individuais (ou grupais), agindo de forma racional e buscando ordenar uma ação coletiva. Já no caso do integrative political processes, os cidadãos agem motivados por um conjunto de valores, constituindo uma noção de identidade comum. (MARCH; OLSEN, 1989, p. 118-119).

Por outro lado, na noção de path dependence está embutida a preocupação com "determinados acidentes de percurso" que acabam determinando todo o processo de desenvolvimento político e econômico de um Estado, inclusive sua propensão à democracia ou ao autoritarismo ou, em outras palavras, a compreensão de determinados regimes políticos a partir de uma sequência de acontecimentos de longo prazo que podem ser remetidos a uma condição inicial, identificada como path dependence. (PIERSON, 2004, p. 20-21).

$O$ resultado principal do enfoque institucional e neoinstitucionalista da democracia foi colocar na agenda o debate sobre o formato institucional e estabilidade democrática. (BAAKLINI; DESFOSSE, 1997). Não obstante, os fatores "condicionantes" ou "determinantes" para a existência, estabilidade ou consolidação dos regimes democráticos permanecem num debate em aberto.

\section{UMA DEMOCRACIA QUANTIFICÁVEL?}

Após a breve exposição das principais teorias e das principais formas de se buscar conceituar o que seria um regime democrático, essa seção se dedica à análise de alguns dados empíricos disponibilizados pela Freedom House.

Contudo, o conjunto de variáveis abordadas nos surveys anuais, produzidos pela Freedon House, extrapola os conceitos minimalistas de democracias de procedimento schumpeteriano e "poliarquias", aproximando-se de uma noção mais ampla de democracia, envolta não apenas por sequências eleitorais, mas também por um enraizamento da cultura cívica, ou capital social, mensurado através do grau de autonomia da sociedade civil, governabilidade e níveis de corrupção. Por essa razão, acredita-se que o conceito de democracia liberal, proposto por Macpherson (1977), seja mais apropriada.

Em outras palavras, como salienta o autor, o fato de que a democracia liberal tenha se constituído como regime político e se desenvolvido sob sistemas econômicos baseados no ca- 
pitalismo, não significa que a correlação entre estes dois fatores seja perene, ou seja, a democracia liberal, como um conjunto de valores baseado na igualdade jurídica entre os cidadãos, respeito aos direitos e garantias individuais, e liberdade de iniciativa e expressão, pode surgir em outros sistemas econômicos que não o capitalismo, ao menos em sua forma mais primitiva. (MACPHERSON, 1977, p.10).

Os dados disponíveis, e compatíveis com o espaço deste artigo, dizem respeito apenas aos novos membros da União Europeia, Leste Europeu e ex-Repúblicas Soviéticas. Não obstante, esse conjunto de países representa o mais recente desafio em termos de consolidação das "democracias de terceira onda".

\subsection{PROCESSOS ELEITORAIS}

O primeiro conjunto de dados analisados diz respeito aos processos eleitorais. A Freedom House utiliza uma escala de valores de 1 a 7 para mensurar o grau de desenvolvimento democrático de determinado país. Quanto mais próximo de 1, maior é o nível de desenvolvimento democrático. No caso inverso, quanto mais próximo de 7, menor é a propensão para a consolidação da democracia. Tais valores são subdivididos pela Freedom House em três categorias; de 1 a 3 livres (ou democráticos), de 4 a 5 parcialmente livres e acima de 5 não-livres, ou regimes autoritários.

As questões incluídas nos surveys anuais da Freedom House, relacionados ao processo eleitoral, procuram identificar a lisura do pleito, da votação à apuração, o grau de liberdade das organizações partidárias, bem como a transparência e a possibilidade de controle dos resultados por parte da sociedade.

Os quadros 1, 2 e 3 mostram a avaliação do processo eleitoral dos países recentemente incluídos na União Europeia, dos Bálcãs e das ex-Repúblicas Soviéticas. ${ }^{3}$

\section{QUADRO 1 - Avaliação do Processo eleitoral dos novos Sócios da União Européia}

\begin{tabular}{|l|c|c|c|c|c|c|c|c|c|}
\hline & 1997 & 1998 & $1999-2000$ & 2001 & 2002 & 2003 & 2004 & 2005 & 2006 \\
\hline República Tcheca & 1.25 & 1.25 & 1.75 & 1.75 & 2.00 & 2.00 & 2.00 & 2.00 & 2.00 \\
\hline Estônia & 2.00 & 1.75 & 1.75 & 1.75 & 1.75 & 1.75 & 1.50 & 1.50 & 1.50 \\
\hline Hungria & 1.25 & 1.25 & 1.25 & 1.25 & 1.25 & 1.25 & 1.25 & 1.25 & 1.25 \\
\hline Latvia & 2.00 & 2.00 & 1.75 & 1.75 & 1.75 & 1.75 & 1.75 & 1.75 & 1.75 \\
\hline Lituânia & 2.00 & 1.75 & 1.75 & 1.75 & 1.75 & 1.75 & 1.75 & 1.75 & 1.75 \\
\hline Polônia & 1.50 & 1.25 & 1.25 & 1.25 & 1.25 & 1.50 & 1.50 & 1.75 & 1.75 \\
\hline Eslováquia & 3.75 & 3.50 & 2.50 & 2.25 & 1.75 & 1.50 & 1.50 & 1.25 & 1.25 \\
\hline Eslovênia & 2.00 & 2.00 & 2.00 & 1.75 & 1.75 & 1.50 & 1.50 & 1.50 & 1.50 \\
\hline Média & 1.97 & 1.84 & 1.75 & 1.69 & 1.66 & 1.63 & 1.59 & 1.59 & 1.59 \\
\hline Mediano & 2.00 & 1.75 & 1.75 & 1.75 & 1.75 & 1.63 & 1.50 & 1.63 & 1.63 \\
\hline
\end{tabular}

FONTE: www.freedomhouse.org

\footnotetext{
${ }^{3}$ Os quadros seguem o critério de classificação geopolítico dos países segundo o estabelecido pela Freedom
} House. 
QUADRO 2 - Avaliação do Processo eleitoral dos Bálcãs

\begin{tabular}{|l|c|c|c|c|c|c|c|c|c|}
\hline & 1997 & 1998 & $1999-2000$ & 2001 & 2002 & 2003 & 2004 & 2005 & 2006 \\
\hline Albânia & 4.25 & 4.50 & 4.25 & 4.00 & 3.75 & 3.75 & 3.75 & 3.75 & 3.50 \\
\hline Bósnia & n/a & 5.00 & 5.00 & 4.75 & 4.25 & 3.75 & 3.50 & 3.25 & 3.00 \\
\hline Bulgária & 3.25 & 2.75 & 2.25 & 2.00 & 2.00 & 2.00 & 1.75 & 1.75 & 1.75 \\
\hline Croácia & 4.00 & 4.25 & 4.25 & 3.25 & 3.25 & 3.25 & 3.25 & 3.00 & 3.25 \\
\hline Macedônia & 3.50 & 3.50 & 3.50 & 3.75 & 4.50 & 3.50 & 3.50 & 3.00 & 3.25 \\
\hline Romênia & 3.25 & 3.25 & 2.75 & 3.00 & 3.00 & 2.75 & 2.75 & 2.75 & 2.75 \\
\hline lugoslávia & n/a & 5.00 & 5.50 & 4.75 & 3.75 & 3.75 & n/a & n/a & n/a \\
\hline Sérvia & n/a & n/a & n/a & n/a & n/a & n/a & 3.50 & 3.25 & 3.25 \\
\hline Montenegro & n/a & n/a & n/a & n/a & n/a & n/a & 3.50 & 3.25 & 3.50 \\
\hline Kosovo & n/a & n/a & n/a & n/a & n/a & n/a & 5.25 & 4.75 & 4.75 \\
\hline Média & 3.65 & 4.06 & 3.93 & 3.64 & 3.50 & 3.25 & 3.42 & 3.19 & 3.22 \\
\hline Mediano & 3.50 & 4.25 & 4.25 & 3.75 & 3.75 & 3.50 & 3.50 & 3.25 & 3.25 \\
\hline
\end{tabular}

FONTE: www.freedomhouse.org

QUADRO 3 - Avaliação do Processo eleitoral nas ex-Repúblicas Soviéticas

\begin{tabular}{|l|l|l|c|c|c|c|c|c|c|}
\hline & 1997 & 1998 & $1990-2000$ & 2001 & 2002 & 2003 & 2004 & 2005 & 2006 \\
\hline Armênia & 5.50 & 5.75 & 5.25 & 5.50 & 5.50 & 5.50 & 5.75 & 5.75 & 5.75 \\
\hline Azerbeidjã & 5.75 & 5.50 & 5.50 & 5.75 & 5.75 & 5.75 & 6.00 & 6.25 & 6.50 \\
\hline Belarus & 6.00 & 6.25 & 6.75 & 6.75 & 6.75 & 6.75 & 6.75 & 7.00 & 7.00 \\
\hline Geórgia & 5.00 & 4.50 & 4.00 & 4.50 & 5.00 & 5.25 & 5.25 & 4.75 & 4.75 \\
\hline Kazakhstan & 5.50 & 5.50 & 6.00 & 6.25 & 6.25 & 6.50 & 6.50 & 6.50 & 6.50 \\
\hline Kirgizstan & 5.00 & 5.00 & 5.00 & 5.75 & 5.75 & 6.00 & 6.00 & 6.00 & 5.75 \\
\hline Moldávia & 3.25 & 3.50 & 3.25 & 3.25 & 3.50 & 3.75 & 4.00 & 4.00 & 3.75 \\
\hline Rússia & 3.50 & 3.50 & 4.00 & 4.25 & 4.50 & 4.75 & 5.50 & 6.00 & 6.25 \\
\hline Tajikistan & 6.00 & 5.75 & 5.50 & 5.25 & 5.25 & 5.25 & 5.75 & 6.00 & 6.25 \\
\hline Turmenistan & 7.00 & 7.00 & 7.00 & 7.00 & 7.00 & 7.00 & 7.00 & 7.00 & 7.00 \\
\hline Ucrânia & 3.25 & 3.50 & 3.50 & 4.00 & 4.50 & 4.00 & 4.25 & 3.50 & 3.25 \\
\hline Uzbekistan & 6.25 & 6.50 & 6.50 & 6.75 & 6.75 & 6.75 & 6.75 & 6.75 & 6.75 \\
\hline Média & 5.17 & 5.19 & 5.19 & 5.42 & 5.54 & 5.60 & 5.79 & 5.79 & 5.79 \\
\hline Mediano & 5.50 & 5.50 & 5.38 & 5.63 & 5.63 & 5.63 & 5.88 & 6.00 & 6.25 \\
\hline
\end{tabular}

FONTE: www.freedomhouse.org

Os quadros 1, 2 e 3 revelam três padrões bastante distintos de processos eleitorais. Enquanto os países recém-incluídos na União Europeia apresentam um nível elevado de democratização do processo eleitoral, com índices que oscilam entre 2.00 e 1.25, as ex-Repúblicas Soviéticas apresentam níveis críticos.

Uma segunda observação relevante a ser feita, ainda em relação aos dois grupos de países acima citados, é que os novos membros da União Europeia demonstram uma tendência geral de consolidação da esfera eleitoral. Já no caso dos países ex-soviéticos, a tendência é de forte corrosão da arena eleitoral, com índices muito próximos do nível 7, o que, para os critérios 
estabelecidos pela Freedom House, significa um distanciamento da democracia e uma aproximação dos autoritarismos.

Os Bálcãs ocupam, neste quesito, uma posição intermediária, mas com um tendência geral de amadurecimento de instituições eleitorais competitivas.

\subsection{AUTONOMIA DA SOCIEDADE CIVIL}

"Sociedade civil" é um conceito polêmico nas ciências e no pensamento social e, certamente, foge aos objetivos deste artigo abordar de modo aprofundado esse tema. Não obstante, de acordo com o que foi exposto na segunda parte deste trabalho, pode-se considerar como "sociedade civil" a esfera da sociedade organizada de forma desvinculada do Estado.

Uma esfera social autônoma representa uma barreira de contenção do poder estatal para Tocqueville (1998 [1980]), fortalecendo deste modo, um regime democrático, bem como uma maneira de elevar o nível de desempenho das instituições governamentais, sobretudo no nível regional e local (PUTNAM, 1996).

Além disso, uma "sociedade civil" organizada também significa uma maior possibilidade de manifestações de opiniões, a favor ou contra o governo. Essas manifestações ocorrem não somente por meio de grupos organizados, mas também por meio da imprensa, e representa critério fundamental para o funcionamento das "poliarquias". (DAHL, 1997 [1972]).

Os dados apresentados nos quadros 4, 5 e 6 mostram a avaliação da Freedom House a respeito do papel da sociedade civil nos países analisados nessa tela. Neste quesito, os surveys procuram identificar o grau de liberdade de organização social e a ausência de controle do Estafo sobre entidades civis.

QUADRO 4 - Avaliação da Sociedade Civil dos novos Sócios da União Europeia

\begin{tabular}{|l|c|c|c|c|c|c|c|c|c|}
\hline & 1997 & 1998 & $1999-2000$ & 2001 & 2002 & 2003 & 2004 & 2005 & 2006 \\
\hline República Tcheca & 1.50 & 1.50 & 1.50 & 1.50 & 1.75 & 1.50 & 1.50 & 1.50 & 1.50 \\
\hline Estônia & 2.25 & 2.25 & 2.50 & 2.25 & 2.00 & 2.00 & 2.00 & 2.00 & 2.00 \\
\hline Hungria & 1.25 & 1.25 & 1.25 & 1.25 & 1.25 & 1.25 & 1.25 & 1.25 & 1.25 \\
\hline Latvia & 2.25 & 2.25 & 2.25 & 2.00 & 2.00 & 2.00 & 2.00 & 1.75 & 1.75 \\
\hline Lituânia & 2.25 & 2.00 & 2.00 & 1.75 & 1.50 & 1.50 & 1.50 & 1.50 & 1.50 \\
\hline Polônia & 1.25 & 1.25 & 1.25 & 1.25 & 1.25 & 1.25 & 1.25 & 1.25 & 1.25 \\
\hline Eslováquia & 3.25 & 3.00 & 2.25 & 2.00 & 1.75 & 1.50 & 1.25 & 1.25 & 1.25 \\
\hline Eslovênia & 2.00 & 2.00 & 1.75 & 1.75 & 1.50 & 1.50 & 1.50 & 1.75 & 1.75 \\
\hline Média & 2.00 & 1.94 & 1.84 & 1.72 & 1.63 & 1.56 & 1.53 & 1.53 & 1.53 \\
\hline Mediano & 2.13 & 2.00 & 1.88 & 1.75 & 1.63 & 1.50 & 1.50 & 1.50 & 1.50 \\
\hline
\end{tabular}

FONTE: www.freedomhouse.org 
QUADRO 5 - Avaliação da Sociedade Civil dos Bálcãs

\begin{tabular}{|l|c|c|c|c|c|c|c|c|}
\hline & 1998 & $1999-2000$ & 2001 & 2002 & 2003 & 2004 & 2005 & 2006 \\
\hline Albânia & 4.25 & 4.25 & 4.00 & 4.00 & 3.75 & 3.75 & 3.50 & 3.25 \\
\hline Bósnia & $\mathrm{n} / \mathrm{a}$ & 5.00 & 4.50 & 4.50 & 4.25 & 4.00 & 3.75 & 3.75 \\
\hline Bulgária & 4.00 & 3.75 & 3.75 & 3.50 & 3.25 & 3.25 & 3.00 & 2.75 \\
\hline Croácia & 3.50 & 3.50 & 3.50 & 2.75 & 2.75 & 3.00 & 3.00 & 3.00 \\
\hline Macedônia & 3.75 & 3.75 & 3.50 & 3.75 & 4.00 & 3.75 & 3.25 & 3.25 \\
\hline Romênia & 3.75 & 3.75 & 3.00 & 3.00 & 3.00 & 2.75 & 2.50 & 2.25 \\
\hline lugoslávia & $\mathrm{n} / \mathrm{a}$ & 5.00 & 5.25 & 4.00 & 3.00 & 2.75 & $\mathrm{n} / \mathrm{a}$ & $\mathrm{n} / \mathrm{a}$ \\
\hline Sérvia & $\mathrm{n} / \mathrm{a}$ & $\mathrm{n} / \mathrm{a}$ & $\mathrm{n} / \mathrm{a}$ & $\mathrm{n} / \mathrm{a}$ & $\mathrm{n} / \mathrm{a}$ & $\mathrm{n} / \mathrm{a}$ & 2.75 & 2.75 \\
\hline Montenegro & $\mathrm{n} / \mathrm{a}$ & $\mathrm{n} / \mathrm{a}$ & $\mathrm{n} / \mathrm{a}$ & $\mathrm{n} / \mathrm{a}$ & $\mathrm{n} / \mathrm{a}$ & $\mathrm{n} / \mathrm{a}$ & 2.75 & 2.50 \\
\hline Kosovo & $\mathrm{n} / \mathrm{a}$ & $\mathrm{n} / \mathrm{a}$ & $\mathrm{n} / \mathrm{a}$ & $\mathrm{n} / \mathrm{a}$ & $\mathrm{n} / \mathrm{a}$ & $\mathrm{n} / \mathrm{a}$ & 4.25 & 4.00 \\
\hline Média & 3.85 & 4.14 & 3.93 & 3.64 & 3.43 & 3.32 & 3.19 & 3.06 \\
\hline Mediano & 3.75 & 3.75 & 3.75 & 3.75 & 3.25 & 3.25 & 3.00 & 3.00 \\
\hline
\end{tabular}

FONTE: www.freedomhouse.org

QUADRO 6 - Avaliação da Sociedade Civil das ex-Repúblicas Soviéticas

\begin{tabular}{|l|c|c|c|c|c|c|c|c|c|}
\hline & 1997 & 1998 & $1999-2000$ & 2001 & 2002 & 2003 & 2004 & 2005 & 2006 \\
\hline Armênia & 3.50 & 3.50 & 3.50 & 3.50 & 3.50 & 3.50 & 3.50 & 3.50 & 3.50 \\
\hline Azerbeidjã & 5.00 & 5.00 & 4.75 & 4.50 & 4.50 & 4.25 & 4.50 & 4.75 & 5.00 \\
\hline Belarus & 5.25 & 5.75 & 6.00 & 6.50 & 6.25 & 6.50 & 6.75 & 6.75 & 6.75 \\
\hline Geórgia & 4.50 & 4.25 & 3.75 & 4.00 & 4.00 & 4.00 & 3.50 & 3.50 & 3.50 \\
\hline Kazakhstan & 5.25 & 5.00 & 5.00 & 5.00 & 5.50 & 5.50 & 5.50 & 5.50 & 5.75 \\
\hline Kirgizstan & 4.50 & 4.50 & 4.50 & 4.50 & 4.50 & 4.50 & 4.50 & 4.50 & 4.50 \\
\hline Moldávia & 3.75 & 3.75 & 3.75 & 3.75 & 4.00 & 3.75 & 4.00 & 4.00 & 4.00 \\
\hline Rússia & 3.75 & 4.00 & 3.75 & 4.00 & 4.00 & 4.25 & 4.50 & 4.75 & 5.00 \\
\hline Tajikistan & 5.50 & 5.25 & 5.25 & 5.00 & 5.00 & 5.00 & 5.00 & 4.75 & 5.00 \\
\hline Turkmenistan & 7.00 & 7.00 & 7.00 & 7.00 & 7.00 & 7.00 & 7.00 & 7.00 & 7.00 \\
\hline Ucrânia & 4.00 & 4.25 & 4.00 & 3.75 & 3.75 & 3.50 & 3.75 & 3.00 & 2.75 \\
\hline Uzbekistan & 6.50 & 6.50 & 6.50 & 6.50 & 6.75 & 6.50 & 6.50 & 6.50 & 7.00 \\
\hline Média & 4.88 & 4.90 & 4.81 & 4.83 & 4.90 & 4.85 & 4.92 & 4.88 & 4.98 \\
\hline Mediano & 4.75 & 4.75 & 4.63 & 4.50 & 4.50 & 4.38 & 4.50 & 4.75 & 5.00 \\
\hline
\end{tabular}

FONTE: www.freedomhouse.org

Nesse segundo quesito analisado, os dados demonstram uma disparidade mais acentuada. Entre os novos membros da União Europeia a avaliação da sociedade civil gira em torno de 1.50 e 2.00, apresentando uma sequência ao longo dos anos de aproximação do que, segundo a Freedom House, seria o nível mais elevado de democratização. A Eslováquia pode ser considera- 
da um caso a parte, pois passa de um patamar de 3.25, em 1997, para atingir, em 2006, o patamar de 1.25 .

Os Bálcãs e as ex-Repúblicas Soviéticas apresentam um baixo índice de democratização das sociedades civis. No caso dos Bálcãs, pode-se dizer que os índices negativos não são tão acentuados como os encontrados nas ex-Repúblicas Soviéticas, que, juntamente com o baixo desenvolvimento de instituições eleitorais, apresentam uma atrofia da esfera societal.

Um último fator a ser ressaltado neste quesito é que não é possível verificar uma tendência à democratização das sociedades civis bálticas e ex-soviéticas, pois, a despeito de alguns avanços na esfera eleitoral, no caso dos Bálcãs, e nenhum avanço no caso das ex-Repúblicas Soviéticas, as liberdades de organização e o desenvolvimento de uma cultura cívica, que se traduza na constituição de um "capital social", mostram-se bastante distantes do patamar das democracias consolidadas.

\subsection{GOVERNABILIDADE}

Um terceiro critério avaliado pela Freedom House é a "governabilidade". Esse termo não possui uma definição exata, ou melhor, embora "governabilidade" seja uma palavra incorporada à língua portuguesa, não se produziu ainda um consenso sobre seu exato significado. Todavia, "governabilidade" pode ser entendida como a capacitação da esfera estatal de implementar suas decisões, seus programas e suas políticas públicas,

Esse quesito é mensurado pela Freedom House como capacidade governamental de executar políticas públicas e a ausência de pressão ou controle de grupos não-estatais, como terroristas, crime organizado etc. sobre a ação governamental.

Os dados apresentados nos quadros 7, 8 e 9 expõem a avaliação da Freedom House acerca do "grau de governabilidade" vigente no conjunto de países aqui estudados.

\section{QUADRO 7 - Avaliação da Governabilidade dos novos Sócios da União Europeia}

\begin{tabular}{|l|c|c|c|c|c|c|c|c|c|c|c|}
\hline & 1997 & 1998 & $1999 / 2000$ & 2001 & 2002 & 2003 & 2004 & 2005 & 2005 & 2006 & 2006 \\
\hline $\begin{array}{l}\text { República } \\
\text { Tcheca }\end{array}$ & 2.00 & 2.00 & 2.00 & 2.00 & 2.25 & 2.25 & 2.25 & 2.50 & 2.00 & 2.50 & 2.00 \\
\hline Estônia & 2.25 & 2.25 & 2.25 & 2.25 & 2.25 & 2.25 & 2.25 & 2.25 & 2.50 & 2.25 & 2.50 \\
\hline Hungria & 1.75 & 1.75 & 2.50 & 3.00 & 3.00 & 2.50 & 2.50 & 2.00 & 2.25 & 2.00 & 2.25 \\
\hline Latvia & 2.50 & 2.50 & 2.50 & 2.25 & 2.25 & 2.25 & 2.25 & 2.25 & 2.50 & 2.00 & 2.50 \\
\hline Lituânia & 2.50 & 2.50 & 2.50 & 2.50 & 2.50 & 2.50 & 2.50 & 2.50 & 2.50 & 2.50 & 2.50 \\
\hline Polônia & 1.75 & 1.75 & 1.75 & 1.75 & 2.00 & 2.00 & 2.00 & 2.50 & 2.00 & 2.75 & 2.00 \\
\hline Eslováquia & 3.75 & 3.75 & 3.00 & 2.75 & 2.25 & 2.25 & 2.25 & 2.00 & 2.25 & 2.00 & 2.00 \\
\hline Eslovênia & 2.50 & 2.50 & 2.25 & 2.50 & 2.25 & 2.25 & 2.00 & 2.00 & 1.50 & 2.00 & 1.50 \\
\hline Média & 2.38 & 2.38 & 2.34 & 2.38 & 2.34 & 2.28 & 2.25 & 2.25 & 2.19 & 2.25 & 2.16 \\
\hline Mediano & 2.38 & 2.38 & 2.38 & 2.38 & 2.25 & 2.25 & 2.25 & 2.25 & 2.25 & 2.13 & 2.13 \\
\hline
\end{tabular}

FONTE: www.freedomhouse.org 
QUADRO 8 - Avaliação da Governabilidade dos Balcãs

\begin{tabular}{|l|c|c|c|c|c|c|c|c|c|}
\hline & 1997 & 1998 & $1999-2000$ & 2001 & 2002 & 2003 & 2004 & 2005 & 2006 \\
\hline Albânia & 4.25 & 4.50 & 4.25 & 4.00 & 3.75 & 3.75 & 3.75 & 3.75 & 3.50 \\
\hline Bósnia & n/a & 5.00 & 5.00 & 4.75 & 4.25 & 3.75 & 3.50 & 3.25 & 3.00 \\
\hline Bulgária & 3.25 & 2.75 & 2.25 & 2.00 & 2.00 & 2.00 & 1.75 & 1.75 & 1.75 \\
\hline Croácia & 4.00 & 4.25 & 4.25 & 3.25 & 3.25 & 3.25 & 3.25 & 3.00 & 3.25 \\
\hline Macedônia & 3.50 & 3.50 & 3.50 & 3.75 & 4.50 & 3.50 & 3.50 & 3.00 & 3.25 \\
\hline Romênia & 3.25 & 3.25 & 2.75 & 3.00 & 3.00 & 2.75 & 2.75 & 2.75 & 2.75 \\
\hline lugoslávia & n/a & 5.00 & 5.50 & 4.75 & 3.75 & 3.75 & n/a & n/a & n/a \\
\hline Sérvia & n/a & n/a & n/a & n/a & n/a & n/a & 3.50 & 3.25 & 3.25 \\
\hline Montenegro & n/a & n/a & n/a & n/a & n/a & n/a & 3.50 & 3.25 & 3.50 \\
\hline Kosovo & n/a & n/a & n/a & n/a & n/a & n/a & 5.25 & 4.75 & 4.75 \\
\hline Média & 3.65 & 4.06 & 3.93 & 3.64 & 3.50 & 3.25 & 3.42 & 3.19 & 3.22 \\
\hline Mediano & 3.50 & 4.25 & 4.25 & 3.75 & 3.75 & 3.50 & 3.50 & 3.25 & 3.25 \\
\hline
\end{tabular}

FONTE: www.freedomhouse.org

QUADRO 9 - Avaliação da Governabilidade das ex-Repúblicas Soviéticas

\begin{tabular}{|l|l|l|l|l|l|l|l|l|l|l|}
\hline & 1997 & 1998 & $\begin{array}{l}1999- \\
2000\end{array}$ & 2001 & 2002 & 2003 & 2004 & 2005 & 2005 & 2006 \\
\hline Armênia & 4.50 & 4.50 & 4.50 & 4.50 & 4.50 & 4.75 & 4.75 & 5.00 & 5.50 & 5.00 \\
\hline Azerbeidjã & 6.25 & 6.25 & 6.25 & 6.25 & 6.00 & 5.75 & 5.75 & 6.00 & 6.00 & 6.00 \\
\hline Belarus & 6.00 & 6.25 & 6.25 & 6.25 & 6.50 & 6.50 & 6.50 & 6.75 & 6.50 & 7.00 \\
\hline Geórgia & 4.50 & 5.00 & 4.50 & 4.75 & 5.00 & 5.50 & 5.75 & 5.50 & 6.00 & 5.50 \\
\hline Kazakhstan & 5.50 & 5.50 & 5.00 & 5.00 & 5.75 & 6.25 & 6.25 & 6.50 & 6.25 & 6.75 \\
\hline Kirgizstan & 4.25 & 4.50 & 5.00 & 5.25 & 5.50 & 6.00 & 6.00 & 6.00 & 5.75 & 6.00 \\
\hline Moldávia & 4.25 & 4.50 & 4.50 & 4.50 & 4.75 & 5.25 & 5.50 & 5.75 & 5.75 & 5.75 \\
\hline Rússia & 4.00 & 4.50 & 4.50 & 5.00 & 5.25 & 5.00 & 5.25 & 5.75 & 5.75 & 6.00 \\
\hline Tajikistan & 7.00 & 6.75 & 6.25 & 6.00 & 6.00 & 6.00 & 5.75 & 6.00 & 5.75 & 6.25 \\
\hline Turkmenistan & 6.75 & 6.75 & 6.75 & 6.75 & 6.75 & 6.75 & 7.00 & 7.00 & 7.00 & 7.00 \\
\hline Ucrânia & 4.50 & 4.75 & 4.75 & 4.75 & 5.00 & 5.00 & 5.25 & 5.00 & 5.25 & 4.50 \\
\hline Uzbekistan & 6.00 & 6.25 & 6.25 & 6.00 & 6.00 & 6.25 & 6.25 & 6.50 & 6.25 & 7.00 \\
\hline Média & 5.29 & 5.46 & 5.38 & 5.42 & 5.58 & 5.75 & 5.83 & 5.98 & 5.98 & 6.06 \\
\hline Mediano & 5.00 & 5.25 & 5.00 & 5.13 & 5.63 & 5.88 & 5.75 & 6.00 & 5.88 & 6.00 \\
\hline
\end{tabular}

FONTE: www.freedomhouse.org

Os dados acerca da governabilidade mostram um distanciamento mais acentuado entre os novos membros da União Europeia e os das outras duas regiões.

Encontra-se, entre os novos membros da União Europeia, uma média de 2.00, com uma leve tendência de declínio do índice de governabilidade. Novamente a Eslováquia representa um caso isolado, com uma taxa menor de capacidade de implementação de ações governamentais. 
Os Bálcãs estão, novamente, em patamar intermediário entre os novos membros da União Europeia e as ex-Repúblicas Soviéticas, com uma leve curva em direção à melhoria da governabilidade, enquanto as ex-Repúblicas Soviéticas apresentam os piores níveis de capacidade governamental.

\subsection{CORRUPÇÃO E ACCOUNTABILITY}

O último quesito analisado empiricamente neste trabalho é a corrupção. A corrupção é uma variável que interfere na consolidação da democracia na medida em que solapa a legitimidade das instituições políticas, fazendo com que procedimentos burocráticos e legais, ocorram sob suspeita, contaminando, desse modo, a adesão às "regras do jogo".

Por outro lado, a corrupção indica a precariedade dos mecanismos de accountability. Esse conceito é, geralmente, empregado para designar a existência de algum tipo de controle por parte dos cidadãos sobre a ação governamental e a prática representativa.

Os surveys da Freedom House consideram, entre os elementos que favorecem a prática de corrupção, a ausência de uma estrutura legal anticorrupção, excesso de burocracia e regulamentação e inexistência de órgãos de auditoria independente e restrições ao jornalismo investigativo.

Os dados apresentados nos quadros 10, 11 e 12 expõem a avaliação da Freedom House acerca do "grau de corrupção" vigente no conjunto de países aqui estudados.

\section{QUADRO 10 - Avaliação da Corrupção dos novos - Sócios da União Européia}

\begin{tabular}{|l|c|c|c|c|c|c|c|c|}
\hline & $1999-2000$ & 2001 & 2002 & 2003 & 2004 & 2005 & 2006 & \\
\hline República & & & & & & & & \\
\hline Tcheca & 3.25 & 3.75 & 3.75 & 3.50 & 3.50 & 3.50 & & \\
\hline Estônia & 3.25 & 2.75 & 2.50 & 2.50 & 2.50 & 2.50 & 2.50 & \\
\hline Hungria & 2.50 & 3.00 & 3.00 & 2.75 & 2.75 & 2.75 & 3.00 & \\
\hline Latvia & & 3.50 & 3.75 & 3.50 & 3.50 & 3.50 & 3.25 & \\
\hline Lituânia & 3.75 & 3.75 & 3.75 & 3.50 & 3.50 & 3.75 & 4.00 & \\
\hline Polônia & 2.25 & 2.25 & 2.25 & 2.50 & 2.50 & 3.00 & 3.25 & \\
\hline Eslováquia & & 3.75 & 3.75 & 3.25 & 3.25 & 3.25 & 3.00 & 3.00 \\
\hline Eslovênia & 2.00 & 2.00 & 2.00 & 2.00 & 2.00 & 2.00 & 2.25 & \\
\hline Média & & 3.09 & 3.03 & 2.94 & 2.94 & 3.00 & 3.09 & \\
\hline Mediano & 3.25 & 3.25 & 3.13 & 3.00 & 3.00 & 3.00 & 3.13 & \\
\hline
\end{tabular}

FONTE: www.freedomhouse.org 
QUADRO 11 - Avaliação da Corrupção dos Balcãs

\begin{tabular}{|l|c|c|c|c|c|c|c|}
\hline & $1999-2000$ & 2001 & 2002 & 2003 & 2004 & 2005 & 2006 \\
\hline Albânia & 6.00 & 5.50 & 5.25 & 5.00 & 5.25 & 5.25 & 5.25 \\
\hline Bósnia & 5.75 & 5.50 & 5.00 & 4.75 & 4.50 & 4.25 & \\
\hline Bulgária & 4.75 & 4.75 & 4.50 & 4.25 & 4.25 & 4.00 & 3.75 \\
\hline Croácia & 5.25 & 4.50 & 4.50 & 4.75 & 4.75 & 4.75 & 4.75 \\
\hline Macedônia & 5.00 & 5.00 & 5.50 & 5.50 & 5.00 & 5.00 & 4.75 \\
\hline Romênia & 4.25 & 4.50 & 4.75 & 4.50 & 4.50 & 4.25 & 4.25 \\
\hline lugoslávia & 6.25 & 6.25 & 5.25 & 5.00 & $\mathrm{n} / \mathrm{a}$ & $\mathrm{n} / \mathrm{a}$ & $\mathrm{n} / \mathrm{a}$ \\
\hline Sérvia & $\mathrm{n} / \mathrm{a}$ & $\mathrm{n} / \mathrm{a}$ & $\mathrm{n} / \mathrm{a}$ & $\mathrm{n} / \mathrm{a}$ & 5.00 & 5.00 & 4.75 \\
\hline Montenegro & $\mathrm{n} / \mathrm{a}$ & $\mathrm{n} / \mathrm{a}$ & $\mathrm{n} / \mathrm{a}$ & $\mathrm{n} / \mathrm{a}$ & 5.25 & 5.25 & 5.25 \\
\hline Kosovo & $\mathrm{n} / \mathrm{a}$ & $\mathrm{n} / \mathrm{a}$ & $\mathrm{n} / \mathrm{a}$ & $\mathrm{n} / \mathrm{a}$ & 6.00 & 6.00 & 6.00 \\
\hline Média & 5.18 & 5.04 & 4.86 & 4.97 & 4.89 & 4.75 & \\
\hline Mediano & 5.25 & 5.00 & 5.25 & 5.00 & 5.00 & 5.00 & 4.75 \\
\hline
\end{tabular}

FONTE: www.freedomhouse.org

QUADRO 12 - Avaliação da Corrupção das ex-Repúblicas Soviéticas

\begin{tabular}{|l|l|l|l|l|l|l|l|}
\hline & $\begin{array}{l}1999 \\
2000\end{array}$ & 2001 & 2002 & 2003 & 2004 & 2005 & 2006 \\
\hline Armênia & 5.75 & 5.75 & 5.75 & 5.75 & 5.75 & 5.75 & 5.75 \\
\hline Azerbeidjã & 6.00 & 6.25 & 6.25 & 6.25 & 6.25 & 6.25 & 6.25 \\
\hline Belarus & 5.25 & 5.25 & 5.25 & 5.50 & 5.75 & 6.00 & 6.25 \\
\hline Geórgia & 5.00 & 5.25 & 5.50 & 5.75 & 6.00 & 5.75 & 5.50 \\
\hline Kazakhstan & 6.00 & 6.25 & 6.25 & 6.25 & 6.50 & 6.50 & 6.50 \\
\hline Kirgizstan & 6.00 & 6.00 & 6.00 & 6.00 & 6.00 & 6.00 & 6.00 \\
\hline Moldávia & 6.00 & 6.00 & 6.25 & 6.25 & 6.25 & 6.25 & 6.00 \\
\hline Rússia & 6.25 & 6.25 & 6.00 & 5.75 & 5.75 & 5.75 & 6.00 \\
\hline Tajikistan & 6.00 & 6.00 & 6.00 & 6.00 & 6.25 & 6.25 & 6.25 \\
\hline Turkmenistan & 6.00 & 6.25 & 6.25 & 6.25 & 6.25 & 6.50 & 6.75 \\
\hline Ucrânia & 6.00 & 6.00 & 6.00 & 5.75 & 5.75 & 5.75 & 5.75 \\
\hline Uzbekistan & 6.00 & 6.00 & 6.00 & 6.00 & 6.00 & 6.00 & 6.50 \\
\hline Média & 5.85 & 5.94 & 5.96 & 5.96 & 6.04 & 6.06 & 6.13 \\
\hline Mediano & 6.00 & 6.00 & 6.00 & 6.00 & 6.00 & 6.00 & 6.13 \\
\hline
\end{tabular}

FONTE: www.freedomhouse.org

Como é possível notar, os mecanismos de combate à corrupção são bastante precários, mesmo entre os novos membros da União Europeia, nos quais os índices médios se mantêm em torno de 3 ao longo dos anos. Cabe observar que os países incluídos nesta categoria apresentam uma tendência geral de elevação do índice de corrupção. 
No caso dos Bálcãs, pode-se notar um patamar de partida, em termos de índices de corrupção, mais elevado do que os encontrados nos novos membros da comunidade Europeia. Contudo, neste segundo caso, os dados mostram uma ligeira tendência de declínio.

Já as ex-Repúblicas Soviéticas apresentam índices alarmantes de corrupção. Neste caso, é possível notar que a prática de corrupção está cristalizada, não sendo possível identificar sinais de reversão de um quadro caótico.

O enfoque sobre a democracia adotado pela Freedom House serve de alerta para os pesquisadores. Embora seja difícil estabelecer parâmetros comparativos a partir de indicadores precisos, capazes de "quantificar a democracia", nem sempre a democratização da arena eleitoral assegura, per si, que outras esferas da sociedade sejam democratizadas e que se produza accountability, ainda que seja praticamente improvável que ocorra qualquer tipo de democratização, sem que existam arenas eleitorais minimamente competitivas.

\section{CONCLUSÃO}

Seria demasiadamente tendencioso afirmar que os dados analisados confirmam a hipótese deste trabalho, qual seja: a de que há um hiato entre o amadurecimento da arena eleitoral e a democratização de outras esferas da sociedade, o que demandaria outro enfoque por parte dos cientistas sociais, que não o estritamente institucionalista.

Em outras palavras, que o fato de haver procedimentos eleitorais nos mais diversos contextos históricos e culturais não retira das ciências sociais a responsabilidade de explicar por que as democracias prosperam em determinados environments e fracassam em outros.

Os dados expostos estão relacionados a democracias em países que, ou derrubaram as ditaduras comunistas nos anos 1990, ou ainda se encontram sob tais regimes ditatoriais. Pode-se dizer que esses países navegam no que seria o "rescaldo" da "terceira onda de democratização", que inicia pelo sul europeu na década de 1970 e atinge a América Latina no final da mesma década (HUNTINGTON, 1994), mas que já emite sinais do que poderia ser visto como uma "onda reversa", ao menos neste último continente (DIAMOND, 1999, p. 61).

Os sinais de que seria factível pensar em uma "onda reversa" ganham alguma relevância, quando analistas do serviço de inteligência dos Estados Unidos projetam, para os próximos anos, um cenário de "crise de governabilidade" e de "riscos para a consolidação da democracia", sobretudo no conjunto de países aqui analisados, mas também em países como a Venezuela (CIA, 2006, p. 87).

Não deixa de ser irônico, contudo, notar que analistas da política interna norte-americana apontam para um declínio da vida associativa e uma forte tendência para um individualismo exacerbado, produzindo, assim, num país de democracia avançada, um enfraquecimento do "capital social" (CRENSON; GINSBERG, 2002), o que demonstra a complexidade das variáveis de pretensão universal.

Fica evidente, a partir dos dados aqui analisados, que a existência de processos eleitorais minimamente competitivos é uma condição essencial para que os sistemas políticos ensaiem um percurso rumo à democratização. Porém, os dados são também passíveis de especulações teóricas, ainda que em caráter preliminar.

A primeira especulação teórica remete ao conceito de path dependence. Tal conceito começa a ganhar robustez quando se volta para o caso das ex-Repúblicas Soviéticas. Mesmo sendo questionável o argumento de Linz e Stepan (1999) a respeito da influência dos regimes autoritários sobre as modalidades de transições e, posteriormente, de consolidação democráti- 
ca, são notórios os percalços desses países até mesmo para se tornarem "democracias concordatórias", segundo o conceito de Rouquié (1985). Isso ocorre em virtude da forte repressão exercida pela ex-União Soviética, após a anexação de pequenas repúblicas situadas no espaço geopolítico de influência comunista.

Uma segunda especulação teórica diz respeito aos novos membros da União Europeia. Nesse caso, fica nítido que o desenho do mundo contemporâneo fez surgir novos atores políticos, entre os quais as instituições supranacionais como o Parlamento Europeu, que impõe regras que condicionam a aceitação ou não de novos sócios (KREPPEL, 2002), fazendo com que um ator externo ganhe alguma relevância e se torne uma variável interveniente que influencie a política interna dos países membros e imponha a adoção de procedimentos democráticos para que tais países possam ser incorporados à comunidade.

Tais regras elevam os custos para que os membros da União Europeia adotem caminhos que os distancie da democracia, uma vez que, ao fazer uma opção autoritária, tais países estão sujeitos a sanções econômicas e a um isolamento que, num mundo de mercados interdependentes, o isolacionismo pode levar qualquer regime político a bancarrota. Resta saber se a modalidade institucional adotada pela União Europeia será do tipo aggregative ou integrative (MARCH; OLSEN, 1989, p. 124-125). No primeiro caso, parece previsível que a simples agregação a uma instituição supranacional, sem uma cooperação mais substantiva, poderá dar um fôlego curto aos empreendimentos democráticos. No segundo caso, se o Parlamento Europeu se constituir como instituição integrativa, é possível ser mais otimista em relação ao futuro democrático dos recém-incluídos na União Europeia.

Por fim, os Bálcãs parecem estar em uma situação intermediária. Segundo a metodologia adotada nos surveys da Freedom House, os Bálcãs não apresentam nem os índices críticos encontrados nas ex-Repúblicas Soviéticas, nem tampouco índices próximos do nível de desenvolvimento democrático apresentado pelos novos membros da União Europeia. Ao que parece, os Bálcãs se encontram no "meio do caminho", podendo tanto vir a se desenvolverem democraticamente, numa perspectiva otimista, como penderem para o lado autoritário, estimulados pelo surgimento de movimentos de nacionalismos extremistas.

O cardápio de variáveis a serem incluídas nas análises sobre processos democráticos é bastante vasto. No entanto, a observação dos fenômenos ocorridos nesse início de século parece demonstrar que a consolidação das democracias não é um destino natural da humanidade. Cabe aos cientistas sociais, não a construção de paradigmas universalmente válidos, mas o esforço intelectual de compreensão dos fatores que geram as condições para a democracia, e das democracias que operam sem condições.

\section{REFERÊNCIAS BIBLIOGRÁFICAS}

BAAKLINI, Abdo; DESFOSSES, Helen (Ed.). Designs of denocraty stability: studies in viable constitutionalism. New York/London: M. E. Sharpe, 1997.

CIA. O relatorio da. Como será o mundo em 2020. São Paulo: Ediouro, 2006.

KREPPEL, Amie. The European Parliament and Supranational Party Sistem: a study in institutional development. Cambridge: Cambridge University Press, 2002.

LIJPHRART, Arend. As democracias contemporâneas: trajectos. Lisboa: Gradiva, 1994. 
CONDIÇÕES PARA A DEMOCRACIA OU DEMOCRACIAS SEM CONDIÇÕES: DILEMAS DE UM PENSAMENTO POLÍTICO CONTEMPORÂNEO

LINZ, Juan J.; STEPAN, Alfred. A transição e consolidação da democracia: a experiência do Sul da Europa e da América do Sul. São Paulo: Paz e Terra, 1999.

LINZ, Juan J.; VALENZUELA, Arturo. (Org.). The failure of presidential democracy: comparative perspectives. v. 1. London: The John Hopkins University Press, 1994.

CRENSON, Matthew A.; GINSBERG, Benjamin. Downsizing democracy: how América sidelined its citizens and privatized its public. Baltimore and London: The John Hopkins University Press, 2002.

DAHL, Robert A. Poliarquia. São Paulo: EDUSP, 1997.

DIAMOND, Larry. Developing democracy: toward consolidation. Baltimore: John Hopkins University Press, 1999.

HUNTINGTON. Samuel P. A ordem política nas sociedades em mudança. Rio de Janeiro: Forense-Universitária, 1975 [1968].

HUNTINGTON, Samuel P. A terceira onda: A democratização no final do século XX. São Paulo: Ática. 1994.

KELSEN, Hans. A democracia. 2 ed. São Paulo, Martins Fontes, 2000 [1955]

LIPSET, Seymour Martin. O homem político. Rio de Janeiro: Zahar, 1967.

MACPHERSON, C. B. A democracia liberal: origens e evolução. Rio de Janeiro: Zahar, 1977.

MARCH, James G.; OLSEN, Johan P. Rediscovering institutions: the organizational basis of politics. New York: The Free Press, 1989.

MARSHALL, T.H.; BOTTOMORE, T. Citizenship and social class. London: Pluto, 1992 [1956].

MUNCK, Gerardo L. Measuring democracy. Maryland: The John Hopkins University Press, 2009.

O’DONNELL, Guillermo. Análise do autoritarismo burocrático. Rio de Janeiro: Paz e Terra, 1990.

PETERS, B. Guy. Political institutions, old and new. In: GOODIN, R. E.; KLINGEMANN, H. D. (Org.). A new handbook of political science. Oxford: Oxford University Press, 1996.

PIERSON, Paul. Politics in time: history, institutions, and social analysis. Princeton: Princeton University Press, 2004.

PUTNAM, Robert D. Comunidade e democracia: a experiência da Itália moderna. Rio de Janeiro: Fundação Getúlio Vargas, 1996.

ROUQUIÉ, Alain. O mistério democrático: das condições da democracia às democracias sem condições. In ROUQUIÉ, A.; LAMOUNIER, B.; SCHVARZER, J. (Org.). Como renascem as democracias. São Paulo: Brasiliense, 1985.

SCHUMPETER, Joseph A. Capitalismo, socialismo e democracia. Rio de Janeiro: Fundo de Cultura, 1968.

TOCQUEVILLE, Alexis de. A democracia na América: leis e costumes. São Paulo: Martins Fontes, 1998 [1980]. 